\title{
Modeling the predictors of stunting in Ethiopia: analysis of 2016 Ethiopian demographic health survey data (EDHS)
}

\author{
Hayelom Gebrekirstos Mengesha ${ }^{1,2^{*}}$, Hassan Vatanparast ${ }^{3}$, Cindy Feng $^{1}$ and Pammla Petrucka ${ }^{4,5}$
}

\begin{abstract}
Background: Despite continued efforts to address malnutrition, there is minimal reduction in the prevalence rates of stunting in developing countries, including Ethiopia. The association between nutritional and socioeconomic factors collected from a national survey in Ethiopia and stunting have not been rigorously analyzed. Therefore, this study aims to model the effect of nutritional and socioeconomic predictors using 2016 Ethiopian Demographic Health Survey (EDHS) data.

Methods: This study is a secondary data analysis of the 2016 EDHS survey, which included 7909 children aged 6 to59 months. Descriptive statistics using frequency and percentage for categorical data and mean and standard deviation for metric data were conducted. Linearity, confounding, and multicollinearity were checked. Bivariable and multivariable logistic regression were carried out. The adjusted odds ratio (AOR) and 95\% confidence interval (Cl) were calculated. A receiver operative curve was built to estimate the sensitivity and specificity of the model.
\end{abstract}

Results: The study identified that 39.2\% of children included in this analysis were stunted. Furthermore, 76.47, 84.27, and $92.62 \%$ of the children did not consume fruits and vegetables, legumes and lentils, or meat and its products, respectively. Children aged 24 months to 59 months were found to be at 9.71 times higher risk of being stunted compared to their younger counterparts aged 6-24 months (AOR: 9.71; Cl: 8.07, 11.6 children). Those children weighing below $9.1 \mathrm{~kg}$ were at 27.86 odds of being stunted compared to those weighing $23.3 \mathrm{~kg}$ and above. Moreover, mothers with a height below $150 \mathrm{~cm}$ (AOR: 2.01; Cl: 1.76, 2.5), living in a rural area (AOR: 1.3, Cl: $1.09,1.54$ ), and being male (AOR: $1.4 ; \mathrm{Cl}: 1.26,1.56)$ were factors associated with stunting. The predictive ability of the model was 77\%: if a pair of observations with stunted and non-stunted children were taken, the model correctly ranks $77 \%$ of such pair of observations.

Conclusion: The model indicates that being born male, being from a mother of short stature, living in rural areas, small child size, mother with mild anemia, father having no formal education or primary education only, having low child weight, and being 24-59 months of age increases the likelihood of stunting. On the other hand, being born of an overweight or obese mother decreases the likelihood of stunting.

Keywords: EDHS, Ethiopia, Stunting, Nutrition, Modeling

\footnotetext{
* Correspondence: hgm745@mail.usask.ca; hayetgeb@gmail.com

'School of Public Health, University of Saskatchewan, Saskatoon, SK, Canada

${ }^{2}$ Adigrat University, College of Medicine and Health Sciences, Adigrat,

Ethiopia

Full list of author information is available at the end of the article
}

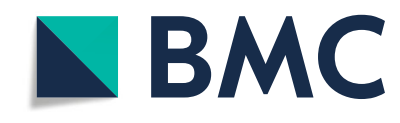

(c) The Author(s). 2020 Open Access This article is licensed under a Creative Commons Attribution 4.0 International License, which permits use, sharing, adaptation, distribution and reproduction in any medium or format, as long as you give appropriate credit to the original author(s) and the source, provide a link to the Creative Commons licence, and indicate if changes were made. The images or other third party material in this article are included in the article's Creative Commons licence, unless indicated otherwise in a credit line to the material. If material is not included in the article's Creative Commons licence and your intended use is not permitted by statutory regulation or exceeds the permitted use, you will need to obtain permission directly from the copyright holder. To view a copy of this licence, visit http://creativecommons.org/licenses/by/4.0/ The Creative Commons Public Domain Dedication waiver (http://creativecommons.org/publicdomain/zero/1.0/) applies to the data made available in this article, unless otherwise stated in a credit line to the data. 


\section{Background}

Nutrition in children, compared to other populations, is critical because childhood is an intense period of mental, physical, and cognitive growth and is highly predictive of future health. Childhood nutrition also reflects long- and short-term negative health consequences, such as reduced economic potential, delayed cognitive development, and educational achievement, along with the increased risk of metabolic syndrome and poor birth outcomes [1-6]. However, macronutrient and micronutrient deficiencies are common during childhood [7] with stunting, wasting, and underweight being the most common nutritional problems affecting millions of children worldwide [8]. According to World Health Organization (WHO) definition, children with height-to-age $\mathrm{z}$-score below minus two standard definition (-2SD) from the median WHO reference population are stunted and those below -3SD are considered to be severely stunted [9]. Chronic malnutrition is highly linked to a lack of adequate nutrient intake during the most critical periods of growth and development of children (i.e. first one thousand days) [10].

Stunting is a global nutritional challenge that disproportionately affects developing nations [8]. It affects 151 million children worldwide, with over $94 \%$ of these cases occurring in Asia and Sub-Saharan Africa (SSA) [8]. According to the 2016 Ethiopian Demographic Health Survey [EDHS], the prevalence of stunting is $38 \%$ [11]. However, not only is the burden of stunting significant, but it has proven to be resistant to resolution showing slow reduction and a nearly constant rate in Ethiopia between 2016 and 2019 [12]. This high prevalence of stunting has far-reaching implications at the individual, community, societal, and national levels.

The factors associated with stunting are diverse and vary across different geographic, ethnic, and social settings and sectors of societies [13-27]. A systematic review and meta-analysis of 21 studies in Africa found that the predictors of stunting were complementary feeding practices, maternal under-nutrition, household food insecurity, economic growth, and maternal education, [13]. In Ethiopia, studies identified different risk factors associated with stunting [14-17].

A study in northern Ethiopia found that being female, belonging to the age group of 25 to 59 months, having a birth weight of $<2.5 \mathrm{~kg}$, lacking antenatal visits, and mistiming of complementary feeding initiation were positively associated with childhood stunting; whereas increasing educational status of the mother showed negative association [14]. However, another study in northeast Ethiopia identified the factors associated with stunting as being male, increasing age, large family size, poor wealth status, illiterate mother, leftover food, living in a rural area, and experiencing less frequent feedings [15]. In addition, a study in northwest Ethiopia revealed that increased age of the child, and family size of six and above were positively associated with stunting, while fathers with secondary school education, farmers as household heads, and self-employed parents as household head were found to be preventive factors [16]. A rigorous analysis of the 2011 EDHS [28] did not include nutritional factors and the predictors that might vary through time [19]. Most studies respecting stunting are cross-sectional with small sample sizes and in specific localities, which is limiting in fully understanding the breadth and complexity of this issue. Therefore, the aim of this study is to determine the predictors associated with stunting in children of 6 months to 59 months using 2016 EDHS data and a best fit model in order to inform national efforts being made to address stunting syndrome in Ethiopia.

\section{Methods}

\section{Participants, study setting and procedures}

The data from 2016 EDHS was collected from January 2016 to June 2016 in nine geographic regions and two administrative cities of Ethiopia. The survey collects data on demographic and health indicators of all household members with specific emphasis on maternal and child health issues. The sampling frame is based on the Ethiopian Population and Housing Census conducted by the Central Statistical Agency in 2007. The sampling frame is a complete list of 84,915 Enumeration Areas (EA), with each EA comprised of 181 households. Sampling was stratified and conducted at two levels. Each region was stratified into urban and rural, producing 21 strata. Sample EA were selected independently from each stratum in two stages by using proportional allocation and implicit stratification.

Accordingly, in the first stage, 202 in urban areas and 443 in rural areas(a total of 645 EAs) were selected with probability proportional to EA size (based on the 2007 Population and Housing Census) and with independent selection in each sampling stratum. In the second stage of selection, a fixed number of 28 households with an equal probability of systematic selection from the newly created list of households per cluster were selected. Detailed sampling procedures and household selection are found elsewhere [11].

\section{Data collection tool}

Five questionnaires were utilized in the 2016 EDHS - the Household Questionnaire, the Woman's Questionnaire, the Man's Questionnaire, the Biomarker Questionnaire, and the Health Facility Questionnaire. All the five questionnaires are presented as an appendix in EDHS 2016 publication [11]. The questionnaires were developed in conjunction with the Demographic Health Survey (DHS), which are customized to an Ethiopian context. 
Since the DHS recodes the original data into different databases, in this study, we used the children's recode with the intention to focus our study on children aged 6 to 59 months.

The children's recode contained data mainly about the households' sociodemographic and other attributes of the children, mothers/caretakers/primary guardians, and fathers/husbands, as well as nutritional, environmental, and health service-related characteristics.

\section{Study variables}

In this study, relevant variables were selected based on previous literature reviews, subject matter knowledge, and the objective of the study, which was determining a best fit model of the nutritional and background factors associated with stunting. For model building, to determine factors associated with stunting, the maximum model was specified by considering a thoughtful causal diagram, reducing the number of predictor variables based on descriptive statistics, conducting correlations analysis to remove highly correlated variables, and creation of indices for select variables and conducting bivariable analysis. In addition, variables with more than $15 \%$ missing values were only described and not included in model building, the effect of continuous variables was also examined, and continuous predictors were tested for linearity.

Based on the above screening procedure, from the sociodemographic and maternal characteristics education of both husband/partner, respondent/ mother highest level of education, age of mother both in a continuous and grouped form, wealth index, residence, sex of child, time to get drinking water, and maternal body mass index $\left(\operatorname{BMI}\left(\mathrm{kg} / \mathrm{m}^{2}\right)\right)$, weight $(\mathrm{kg})$, and height $(\mathrm{cm})$ and anemia. Lightweight SECA with a digital screen designed and manufactured under the guidance of UNICEF motherinfant scales were used to measure weight. A Shorr measuring board was used to measure height of children. Children younger than 24 months were measured for height while lying down, and older children were measured while standing.

Anemia was measured in terms of hemoglobin level in grams/deciliter. Anemia in children is categorized as follows:

1. Non-anemic: Number of children whose hemoglobin count is $11 \mathrm{~g}$ per deciliter $(\mathrm{g} / \mathrm{dl})$ or higher.

2. Mild anemia: Number of children whose hemoglobin count is between 10.0 and $10.9 \mathrm{~g}$ per deciliter $(\mathrm{g} / \mathrm{dl})$.

3. Moderate anemia: Number of children whose hemoglobin count is between 7.0 and $9.9 \mathrm{~g}$ per deciliter $(\mathrm{g} / \mathrm{dl})$.
4. Severe anemia: Number of children whose hemoglobin count is less than $7.0 \mathrm{~g}$ per deciliter $(\mathrm{g} / \mathrm{dl})$.

Details of data collection procedure on the measurement of blood hemoglobin and anemia categorization for children and women are presented in EDHS 2016 [11].

Child size is the mother's subjective estimate of baby's size at the time of birth in the 5 years before the survey. By Percent distribution of births by the size of baby at birth, child size is classified into: very small, smaller than average, average, larger and don't know/missing. This estimate was obtained because birth weight is unknown for most (86\%) newborns in Ethiopia [11].

Education was categorized into no education, primary, secondary, and tertiary. Age of the respondents was initially categorized primarily into seven 5 -year groups, but, during analysis, it was re-categorized into four groups (15-19, 20-29, 30-39, 40-49).

The wealth index indicates a composite measure of a household's cumulative living standard. It is calculated using easy-to-collect data on a household's ownership of selected assets, such as televisions and bicycles, materials used for housing construction; and types of water access and sanitation facilities. Wealth index was classified into five groups: poorest, poorer, middle, richer, and richest [11]. However, for the sake of analysis, wealth was recategorized into 3 groups: poor, average, and rich. The details of construction are attached as supplementary material (S1).

Time to get drinking (potable) water was in a continuous form but categorized into less than $30 \mathrm{~min}$ or above or equal to $30 \mathrm{~min}$ walk. The details of EDHS variables code, including the transformations we made in this study and other details were explained as supplement file.

Regarding the dietary intake of children, the data was based on a 24-h recall (day and night before the interview) by the mother who was asked if she had a child living with her who was born after 2014. If her response was affirmative, the mother was asked if she gave the child certain food group selections. Based on this response, we created five groups according to WHO indicators [29] which included: Fruits and vegetables; Grains, roots and tubers; Legumes and lentils; Dairy products; Meat and its products. Table 1 shows the details of categorization and is attached as a supplement file.

\section{Data management and analysis}

Data were cleaned and analyzed in SAS ${ }^{\mathrm{mi}}$ 9.4. Categorical variables were described using frequency and percentages. For continuous variables, mean and standard deviation (SD) were used. Cross-tabulations between some predictor and outcome variables were conducted to check 
Table 1 Sociodemographic and economic characteristics of households $(N=7909)$

\begin{tabular}{|c|c|c|}
\hline Variable & Frequency & $\%$ \\
\hline \multicolumn{3}{|c|}{ Age of mother at delivery } \\
\hline $15-19$ & 240 & 3.03 \\
\hline $20-29$ & 3933 & 49.73 \\
\hline $30-39$ & 3065 & 38.75 \\
\hline $40-49$ & 671 & 8.48 \\
\hline \multicolumn{3}{|c|}{ Time to access clean water $(n=6503)$} \\
\hline$<30 \min$ & 3748 & 57.63 \\
\hline$\geq 30 \mathrm{~min}$ & 2755 & 42.37 \\
\hline Missing & 1406 & \\
\hline \multicolumn{3}{|c|}{ Paternal educational attainment } \\
\hline No education & 3592 & 48.21 \\
\hline Primary only & 2484 & 33.34 \\
\hline Secondary & 754 & 10.20 \\
\hline Tertiary & 564 & 7.63 \\
\hline \multicolumn{3}{|c|}{ Age child(in months) } \\
\hline 6 to 24 & 2919 & 36.91 \\
\hline$>24$ to 59 & 4990 & 63.09 \\
\hline \multicolumn{3}{|l|}{ Residence } \\
\hline Urban & 1452 & 18.36 \\
\hline Rural & 6457 & 81.64 \\
\hline \multicolumn{3}{|c|}{ Maternal educational attainment } \\
\hline No education & 5092 & 64.38 \\
\hline Primary only & 2021 & 25.55 \\
\hline Secondary & 513 & 6.49 \\
\hline Tertiary & 283 & 3.58 \\
\hline \multicolumn{3}{|l|}{ Wealth index } \\
\hline Poorest & 2821 & 35.67 \\
\hline Poorer & 1396 & 17.65 \\
\hline Middle & 1161 & 14.68 \\
\hline Richer & 987 & 12.48 \\
\hline Richest & 1544 & 19.52 \\
\hline \multicolumn{3}{|l|}{ Sex of child } \\
\hline Male & 4454 & 51.26 \\
\hline Female & 3855 & 48.74 \\
\hline \multicolumn{3}{|l|}{ Birth interval } \\
\hline$<24$ month & 1533 & 24.14 \\
\hline$\geq 24$ month & 4817 & 75.86 \\
\hline Missing & 1559 & \\
\hline
\end{tabular}

assumptions. Histograms and quartiles were used to present data. For ordinal variables, we used the Spearman correlation. For continuous variables, we used the Pearson correlation to check the correlation between independent predictors, with $r \geq 0.7$ used as the cut-off value for correlation. Multi-collinearity was checked using the variance inflation factor (VIF) with VIF $<2.5$ used as a cut-off point. Interaction and confounders were tested. The interaction was checked among pairs of variables that were suspected of having interactions based on prior knowledge and literature. A bivariable logistic regression analysis using an Unadjusted Odds Ratio (UOR) was carried out to select candidate variables with $P$-values of $<0.25$ for multivariable logistic regression model building. In multivariable logistic regression analysis model building, backward elimination was used. Finally, variables with a $P$-value of 0.05 with $95 \%$ confidence interval (CI) and adjusted odds ratio (AOR) were conducted. A receiver operative characteristics curve (ROC) with sensitivity and specificity was also depicted to determine the predictive ability of the model. Model goodness-of-fit was assessed by using the Hosmer and Lemeshow test. Linearity was assessed by comparing the squared variable with un-squared variable significance; if the squared variable was significant, the variable was classified into plausible categories. A model selection for non-nested models was done using Akaike's Information Criteria (AIC), and a model with smaller values was selected.

\section{Results}

\section{Participants' sociodemographic summary}

In the original recoded children data, there were10641 children under five and 1209 variables. On rigorous data cleaning and management process, 32 variables and 7909 children with mothers were included in the analysis.

\section{Sociodemographic characteristics of $6-59$ months old children}

Regarding the place of residence, more than $80 \%$ of the children resided in rural areas. Nearly half of the husbands/partners had no education, and $4217(52 \%)$ were categorized in the poor category of wealth status. See Table 1 for details.

\section{Description of nutritional characteristics of children aged 6-59 months}

The prevalence of stunting in this population was $39.1 \%$. A few (10\%) children were given dairy products, which included yogurt and cheese, by their mothers/caretakers. The most common foods eaten were grains and tubers, which were consumed by almost half of the children. Less than a quarter of children consumed fruits and vegetables (23.53\%), with the lowest food group consumed being meat $(7.38 \%)$ and its products followed by legumes and lentils (15.73\%). There were large missing value sets for this factor because mothers/caretakers were only asked for children born in 2014 or later and limited to one child per household. See details in Table 2. 
Table 2 Nutritional and clinical characteristics of mothers and children 6-59 months

\begin{tabular}{lll}
\hline Variable & Freq. & $\%$ \\
\hline $\begin{array}{ll}\text { Stunting } \\
\text { Yes }\end{array}$ & 3101 & 39.21 \\
No & 4808 & 60.79 \\
Dairy products $(\boldsymbol{n}=\mathbf{4 7 7 0})$ & & \\
No & 3929 & 82.36 \\
Yes & 841 & 17.64 \\
Missing & 3139 &
\end{tabular}

Grains, roots, and tubers (Gratube) $(n=4770)$

$\begin{array}{lll}\text { No } & 2333 & 48.9 \\ \text { Yes } & 2437 & 51.1\end{array}$

Missing 3139

Fruits and vegetables (Fruveg) $(n=4770)$

$\begin{array}{lll}\text { No } & 3648 & 76.47 \\ \text { Yes } & 1122 & 23.53 \\ \text { Missing } & 3139 & \end{array}$

Meat and its products $(n=4770)$

$\begin{array}{ll}\text { No } & 4418 \\ \text { Yes } & 352 \\ \text { Missing } & 3139 \\ \text { Legumes and lentils }(\boldsymbol{n}=\mathbf{4 7 7 0}) & \\ \text { Yes } & 750 \\ \text { No } & 4020 \\ \text { Missing } & 3139\end{array}$

Size of child

$\begin{array}{lll}\text { Large } & 2419 & 30.85 \\ \text { Average } & 3353 & 42.77 \\ \text { Small } & 2068 & 26.38 \\ \text { Missing } & 69 & \\ \text { Maternal height } & & \\ <150 \mathrm{~cm} & 776 & 9.81 \\ >=150 \mathrm{~cm} & 7133 & 90.19\end{array}$

Anemia level of the mother $(n=7609)$

$\begin{array}{lll}\text { Severe } & 126 & 1.64 \\ \text { Moderate } & 730 & 9.48 \\ \text { Mild } & 1795 & 23.32 \\ \text { Not anemic } & 5046 & 65.56 \\ \text { MII }^{\mathbf{a}} \text { of mother } & & \\ <18.5 & 1921 & 24.29 \\ 18.5-24.9 & 5174 & 65.42 \\ \geq 25 & 722 & 9.13 \\ \text { Missing } & 92 & 1.16 \\ \text { Anemia level of the child } & & \\ \text { Severe } & 300 & 3.94\end{array}$

Table 2 Nutritional and clinical characteristics of mothers and children 6-59 months (Continued)

\begin{tabular}{lll}
\hline Variable & Freq. & $\%$ \\
\hline Moderate & 2455 & 32.22 \\
Mild & 1812 & 23.78 \\
Not anemic & 3052 & 40.06 \\
Missing & 290 & \\
Weight of child & & \\
$<9.1 \mathrm{~kg}$ & 1948 & 2463 \\
$\geq 9.1-11.1 \mathrm{~kg}$ & 1964 & 2483 \\
$\geq 11.2-13.3 \mathrm{~kg}$ & 2005 & 2535 \\
$>13.3 \mathrm{~kg}$ & 1992 & 2519 \\
\hline
\end{tabular}

${ }^{\mathrm{a} B o d y}$ mass index; ${ }^{\mathrm{b}}$ kilogram

\section{Description of continuous variables}

The average age of women who participated in the survey was 29.4 (6.5) years, and the average weight of the child during the survey was $11.3(2.8) \mathrm{kg}$ (see Table 3 for details).

\section{Correlation and linearity of independent variables}

Simple Pearson correlation was conducted for continuous variables. However, Spearman correlation was used for ordered categorical variables. Based on these tests significant correlation was not obtained. The correlation was considered significant if $r$ was above $70 \%$. Based on this level, there was no significant correlation among the independent variables.

The linearity of selected independent variables was checked with weight of the child squared found to be significant in the model. The quadratic form of the variable was significant and considering this, the interaction term was included in the final model; however, it created instability in the model due to high collinearity with the normal variable (unsquared weight of the child). Therefore, the weight of the child was categorized into quartiles.

Table 3 Mean and standard deviation of continuous variables of children 6-59 months old in Ethiopia of 2016 EDHS

\begin{tabular}{lll}
\hline Variable & Mean & SD $^{\mathbf{b}}$ \\
\hline Age of mother $(n=7909)$ in years & 29.45 & 6.5 \\
Time to access clean water $(n=6503)$ in minutes & 57.93 & 75.84 \\
Number of children $(n=7909)$ & 1.85 & 0.81 \\
Weight mother $(n=7820)$ in $\mathrm{kg}$ & 51.7 & 9.29 \\
Height mother $(n=7821)$ in $\mathrm{m}$ & 1.58 & 0.68 \\
BMl ${ }^{\mathrm{a}}$ mother $(n=7817)$ in $\mathrm{kg} / \mathrm{m}^{2}$ & 20.66 & 3.34 \\
Weight child $(n=7907)$ in $\mathrm{kg}$ & 11.3 & 2.8 \\
Height of child $(n=7909)$ in m & 0.85 & 0.116 \\
\hline aody mass index; ${ }^{\mathrm{b}}$ standard deviation & &
\end{tabular}




\section{Bivariable analysis and multi-collinearity}

The bivariable analysis showed that maternal factors including height, anemia level, education, and BMI; child factors including age, anemia level, weight, sex, and size; paternal education; and place of residence (urban/rural) were significantly associated with stunting (see Table 4).

Based on restrictive multi-collinearity test values of $\geq 2.5$, there was no multi-collinearity between the independent variables found in this study.

\section{Predictors of stunting}

After a rigorous screening, steps were taken to select candidate variables, such as mothers' education because of a small number of observation in the third category and moderate correlation with husband education, all children food intake history (fruits and vegetables, grains, tubers and roots, lentils and legumes, meat groups and dairy products), birth intervals, and number of children were excluded because of missing values. Based on this screening, after wealth and anemia of the child were excluded during model building, while maternal height, child size, paternal education, age and sex of child, residence, BMI of the mother, anemia level of the mother, and weight of child were all independent predictors of stunting in our study.

Mothers who were below $150 \mathrm{~cm}$ tall were at a 2.01 times increased risk of having stunted children compared to mothers who were $150 \mathrm{~cm}$ or above (AOR: 2.01; CI: 1.76, 2.5). Age of the child and weight of the child during the interview were strong factors associated with stunting. Children aged 24 to 59 months were at a 9.71 times higher risk of being stunted compared to younger children aged 6 to 24 months old (AOR: 9.71; CI: 8.07,11.6). Similarly, children weighing less than 9.1 $\mathrm{kg}$ were at 27.86 odds of being stunted compared to those weighing $23.3 \mathrm{~kg}$ and above. From the sociodemographic determinants, living in a rural area increases the odds of stunting by $30 \%$ than living in the urban areas (AOR: 1.3; CI: 1.09, 1.54). From the unavoidable factors, sex of the child, being male, increase the odds of stunting by $40 \%$ than their female counterparts (AOR: 1.4; CI: $1.26,1.56$ ) [see Table 5 for details].

\section{Result of interaction test in the final model}

There was no significant interaction found among the independent factors affecting stunting. Interaction was tested based on previous literature and knowledge of the subject matter. Interaction was tested between age of the child and weight of the child, education and anemia level, height of the mother and BMI.

\section{Goodness of fit of the model}

The model developed in this study fits the data well $(P=0.85)$. We choose the Hosmer and Lemeshow goodness fit test because our study contained too many categories, and the number of unique profiles were 1823 .

\section{Predictive ability of the model}

Comparing different non-nested models Non-nested models were compared using AIC value for select continuous variables like the weight of the child versus the categorical weight of child; the height of mother in meters versus categorized height of the mother, and age of the child in months versus categorical age in months. We chose a model with the smaller AIC value which, in this case, was the categorized form of the variables (Fig. $1)$.

\section{Discussion}

The aim of this study was to model the predictors of stunting using a dataset that is representative of the nation, and the findings could possibly be put in to practice. To the best of our knowledge, this is the first study that analyzed the 2016 EDHS and considered nutritional factors and dietary patterns, developed a model, and rigorously tested for its fitness. The model will open the door for future studies to be conducted and improve the Area under the curve (AUC), sensitivity and specificity of the model by including other important factors that are not measured in this study. Therefore, the prevalence of stunting in included children of 6 to 59 months found to be $39.1 \%$. More importantly, we found that children aged above 24 months, low weight, small size, being male at birth, short maternal stature, overweight and obese maternal status, rural residence, no education and primary education of husband, and mild anemia of the mother were predictors of stunting. Among this child age, low weight, and maternal stature were the strongest predictors with AOR above 2 .

Child age above $24-59$ months was strongly associated with stunting with the AOR above 2. A number of studies have found similar associations [14, 17, 19]. This evidence corroborates that stunting is malnutrition, which starts during pregnancy and continues until the second year of life with the most frequent appearance after the second year of life [6]. However, this finding does not mean intervening after the second year of life is not effective as there are numerous immediate avoidable factors that, if intervened, may reduce the effects of stunting after the second year of life. Studies have shown that factors associated with stunting in late childhood and adolescence are different, and there are other windows of opportunities to stop chronic malnutrition if the first 1000 years window is missed [30]. Regardless, our study finding reaffirms that, to reduce stunting, intervention strategies ideally will focus on the child before 24 months. 
Table 4 Bi-variable analysis and cross-tabulation of the outcome variable versus the covariates in children of age 6-59 months using 2016 EDHS dataset

\begin{tabular}{|c|c|c|c|c|c|}
\hline Variable & Stunting & & UOR & $95 \% \mathrm{Cl}$ & $P$-va \\
\hline & No, freq(\%) & Yes, freq(\%) & & & \\
\hline \multicolumn{6}{|c|}{ Age of mother } \\
\hline $15-19$ & 138(1.74) & 102(1.29) & ref & ref & \\
\hline $20-29$ & 2404(30.4) & 1529(19.33) & 1.16 & $0.89,1.51$ & 0.22 \\
\hline 30-39 & 1866(23.59) & 1199(15.16) & 1.15 & $0.88,1.5$ & 0.33 \\
\hline $40-49$ & $400(5.06)$ & $271(3.43)$ & 1.09 & $0.80,1.47$ & 0.91 \\
\hline
\end{tabular}

Overall $p$-value $=0.643$

Maternal height

$$
\begin{aligned}
& \geq 150 \mathrm{~cm} \\
& <150 \mathrm{~cm}
\end{aligned}
$$

$4461(56.4)$

$347(4.39)$

2672(33.78)

429(5.42)

$48(0.62)$

302(3.92)

759(9.86)

1913(24.85)

Not anemic

\section{Anemia level of child}

Severe

Mild

Non-anemic

Overall $P$-value $=0.0069$

\section{Child size}

Large
Average
Small

\section{Paternal education}

No education
Primary
Secondary
Tertiary

\section{Maternal education}

No education
Primary
Secondary
Tertiary

\section{Age child}

6 to 24 months

$\geq 24$ to 59

\section{Wealth index}

Poor
Average
Rich

1608(20.51)

2059(26.26)

1099(14.02)

$135(1.77)$
$1425(18.7)$
$1075(14.11)$
$1962(25.75)$

165(2.17)

1030(13.52)

737(9.67)

1090(14.31)

$811(10.34)$
$1294(16.51)$
$969(12.36)$

1993(26.95)

1537(20.79)

525(7.10)

441(5.96)

$2899(36.65)$
$1281(16.26)$
$388(4.91)$
$240(3.03)$

2017(25.5)

2791(35.29)

2321(29.35)

695(8.79)

1792(22.66)
969(12.36)

1599(21.63)

947(12.81)

229(3.10)

123(1.66)

2193(27.73)

740(9.36)

125(1.58)

43(0.54)

902(11.4)

2199(27.8)

1896(23.97)

$466(5.890$

739(9.34)
1.62

ref ref

2.06

ref

$1.77-2.39$

ref

$<0.0001$

1.008

1.15

1.2

ref

2.2

1.3

1.23

ref

$0.7,1.45$

$0.98,1.35$

$1.07,1.33$

ref

0.96

0.07

0.0011

ref

$1.73,2.79$

$<0.0001$

$1.16,1.45$

$<0.0001$

$1.09,1.39$

0.0006

ref

ref

ref

$1.11,1.39$

$<0.0001$

$1.54,1.97$

$<0.0001$

1.74

2.87

2.2

$2.33,3.55$

$<0.0001$

$1.78,2.74$

$<0.0001$

$1.21,2.01$

0.0005

ref

$3.03,5.86$
$2.3,4.5$
$1.22,2.63$
ref

$<0.0001$

$<0.0001$

0.0026

ref

ref

1.6,1.94

$<0.0001$

1.76

$1.78,2.2$

$<0.0001$

$1.4,1.88$

$<0.0001$ 
Table 4 Bi-variable analysis and cross-tabulation of the outcome variable versus the covariates in children of age 6-59 months using 2016 EDHS dataset (Continued)

\begin{tabular}{|c|c|c|c|c|c|}
\hline \multirow{2}{*}{$\begin{array}{l}\text { Variable } \\
\text { Sex of child }\end{array}$} & \multicolumn{2}{|l|}{ Stunting } & \multirow[t]{2}{*}{ UOR } & \multirow[t]{2}{*}{$95 \% \mathrm{Cl}$} & \multirow[t]{2}{*}{$P$-value } \\
\hline & & & & & \\
\hline Male & $2400(30.35)$ & $1654(20.91)$ & 1.14 & $1.04,1.25$ & 0.003 \\
\hline Female & $2408(30.45)$ & $1,447,918.3)$ & ref & ref & \\
\hline \multicolumn{6}{|l|}{ Residence } \\
\hline Urban & 1076(13.6) & $376(4.75)$ & ref & ref & \\
\hline Rural & $3732(47.19)$ & $2725(34.45)$ & 2.09 & $1.84,2.37$ & $<0.0001$ \\
\hline \multicolumn{6}{|l|}{ BMI of mother } \\
\hline$<18.5$ & 1094(14) & $827(10.58)$ & 1.13 & $1.02,1.26$ & 0.018 \\
\hline$\geq 18.5-24.9$ & 3107(39.75) & $2067(26.44)$ & ref & ref & \\
\hline$\geq 25$ & $556(7.11)$ & $166(2.12)$ & 0.44 & $0.37,0.53$ & $<0.0001$ \\
\hline \multicolumn{6}{|l|}{ Weight child } \\
\hline$<9.1$ & $1117(14.12)$ & $830(10.51)$ & 3.81 & $3.28,4.42$ & \\
\hline$\geq 9.1-11.2$ & $956(12.09)$ & $1008(12.74)$ & 5.4 & $4.66,6.27$ & \\
\hline$\geq 11.2-13.3$ & $1068(13.5)$ & $937(11.85)$ & 4.5 & $3.88,5.21$ & \\
\hline$>13.3$ & 1667(21.08) & $325(4.11)$ & ref & ref & \\
\hline Continuous variables & \multicolumn{2}{|c|}{ B-coefficient Cl } & \multicolumn{2}{|l|}{$P$-value } & \\
\hline Age of mother & 1.003 & $0.997,1.01$ & 0.325 & & \\
\hline Weight of child & 0.983 & $0.981,0.985$ & 0.0001 & & \\
\hline Height of mother & 0.995 & $0.994,0.995$ & $<0.0001$ & & \\
\hline
\end{tabular}

UOR unadjusted odds ratio, Freq frequency, $\mathrm{Cl}$ confidence interval

Therefore, policies and interventions should focus on the first one thousand days to prevent the stunting incidence. Equally important, the period between 24 and 59 months is crucial to provide a personalized intervention, such as providing specific nutritional needs for children with stunting, to accelerate catchup growth.

The current weight of the child was the strongest predictor of stunting, according to the 2016 EDHS data. The continuous form of the variable was shown in a non-linear relationship (quadratic) with stunting. Consequently, the variable is categorized into quartiles. There are no previous studies that assessed the effect of child weight on stunting directly, although studies have shown that wasting (weight to height) is associated with stunting $[22,23]$, low birth weight is associated with stunting [14], and weight to-age are indicators which reflect cumulative effects of wasting and stunting [11]. The association between child weight and stunting could be very strong because there are a few children with a large weight and being stunted at the same time; hence, this could inflate the association. Children's weights reflect body composition with a recent study finding that stunted mothers have low body composition, including small kidneys and other organs, are thin, and give birth to small infants [31]. The implication of this finding is that weight monitoring of children is critical in preventing and intervening in cases of stunting. Prospective future studies need to assess the effectiveness of weight monitoring overtime on stunting incidence.

Maternal stature was one of the independent predictors of stunting. Different study findings were in line with our findings [21, 27]. Maternal stature reflects the intergenerational effects of stunting, maternal malnutrition, and its consequences on childhood outcomes [6]. This knowledge suggests that focusing on mothers of short stature might help in improving birth outcomes and in following-up of children after birth. However, the maternal stature cut-off point we used was arbitrary as there is no universally agreed cut-off point in the literature. Intuitively, the cut-off point should be locally derived as genetics may also have a role in determining one's height. This observation could be similarly applied to stunting's definition which might not be a perfect indicator of malnutrition as linear growth failure may be caused by different biological causes apart from inadequate nutrition [32].

In addition, maternal BMI, rural residence, paternal education, being male, and child's size were important independent predictors. These findings are similar to those of recent literature $[14,15,19,20,24]$. 
Table 5 Multivariable analysis of variables included in the final model of children age between 6 months and 59 months included in 2016 EDHS

\begin{tabular}{|c|c|c|}
\hline Variable & AOR & $95 \% \mathrm{Cl}$ \\
\hline \multicolumn{3}{|l|}{ Maternal height } \\
\hline$\geq 150 \mathrm{~cm}$ & Ref & Ref \\
\hline$<150 \mathrm{~cm}$ & 2.01 & $1.76,2.5$ \\
\hline \multicolumn{3}{|l|}{ Child size } \\
\hline Large & Ref & ref \\
\hline Average & 1.12 & $0.98,1.27$ \\
\hline Small & 1.38 & $1.19,1.59$ \\
\hline \multicolumn{3}{|l|}{ Paternal education } \\
\hline No education & 1.79 & $1.39,2.3$ \\
\hline Primary & 1.62 & $1.25,2.1$ \\
\hline secondary & 1.32 & $0.99,1.77$ \\
\hline tertiary & Ref & ref \\
\hline \multicolumn{3}{|l|}{ Age child } \\
\hline 6 to 24 months & Ref & ref \\
\hline$>24$ to 59 months & 9.71 & $8.07,11.6$ \\
\hline \multicolumn{3}{|l|}{ Sex of child } \\
\hline Male & 1.4 & $1.26,1.56$ \\
\hline Female & ref & ref \\
\hline \multicolumn{3}{|l|}{ Residence } \\
\hline Urban & ref & ref \\
\hline Rural & 1.3 & $1.09,1.54$ \\
\hline \multicolumn{3}{|l|}{ BMI of mother } \\
\hline$<18.5$ & 1.02 & $0.9,1.16$ \\
\hline$\geq 18.5-24.9$ & ref & ref \\
\hline$\geq 25-29.9$ & 0.69 & $0.54,0.89$ \\
\hline$\geq 30$ & 0.59 & $0.37,0.94$ \\
\hline \multicolumn{3}{|c|}{ Anemia level of mother } \\
\hline Severe & 0.73 & $0.48,1.11$ \\
\hline Moderate & 0.92 & $0.76,1.11$ \\
\hline Mild & 1.14 & $1.1,1.3$ \\
\hline Not anemic & ref & ref \\
\hline \multicolumn{3}{|l|}{ Weight of child } \\
\hline$<9.1$ & 27.8 & $21.8,35.38$ \\
\hline 9.1 to 11.2 & 15.64 & $12.91,18.95$ \\
\hline 11.2 to 13.3 & 5.19 & $4.41,6.10$ \\
\hline$>13.3$ & ref & ref \\
\hline
\end{tabular}

AOR Adjusted odds ratio, $\mathrm{Cl}$ confidence interval, BMI Body mass index

Although there is some contrasting evidence regarding the association of sex with stunting [14], most studies' findings indicated male children are more likely to be affected by stunting $[15,16,19,26]$, which could be due to biological or metabolic

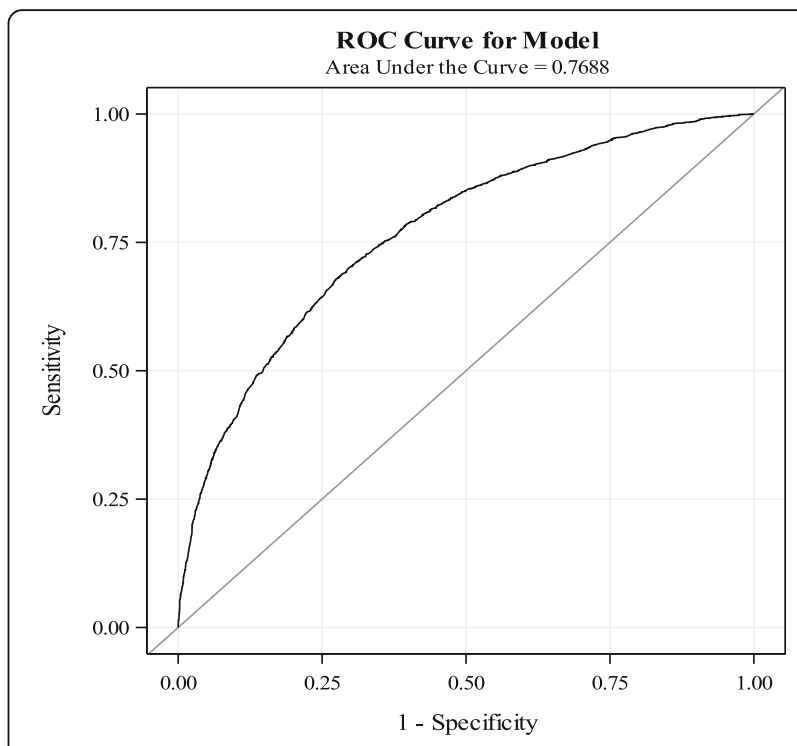

Fig. 1 Receiver operating characteristics curve for the model developed on stunting predictors. The area under the curve (AUC) in our model was found to be 0.7688 which is equals to $77 \%$. This means a randomly selected individual from the stunting group has a true test value larger than that for a randomly chosen individual from the non-stunted group $77 \%$ of the time. Such that if a pair of observations with stunted and nonstunted children were taken the model ranks $77 \%$ of such pairs of observations correctly

differences across sexes [33]. A meta-analysis of 16 demography health surveys conducted in SSA concluded that male children under 5 years of age are more likely to become stunted than females, which might suggest that boys are more vulnerable to health inequalities than their female counterparts in the same age groups [34]. Further studies are required to uncover the reason behind this finding. Policies and interventions that on stunting reduction need to place a due emphasis on gender differentials.

Education is also a well-established factor for the likelihood stunting. Previous studies have found a similar association [19, 26]. Stunting is a complex problem correlated with the socioeconomic level of a society and a nation at large. Achieving the sustainable development goals is addressing the problem of stunting indirectly [35]. However, since stunting affects generations, hundreds of millions of individuals are already stunted, so intervention strategies should focus not only first 1000 years but also on these different population groups to stop the stunting syndrome as there might be other windows of opportunities for intervention [30].

The prevalence of stunting has decreased by about $1 \%$ every year from 58\% in 2000 to $38 \%$ in 2016 [11, 36] and unexpectedly has shown almost no reduction between 2016 and 2019 at 37\% [11, 12]. It has increased in some regions of Ethiopia, such as in Tigray region; it has 
increased by almost $10 \%$ from $38 \%$ in 2016 to $48.7 \%$ 2019 [11, 12]. This probably indicates the failure to design workable policies and locally based interventions. Particularly, data on dietary intake were not collected and analyzed in previous demographic surveys. Therefore, this study gives an important insight to design programs and policies based on the local evidence to prevent and address stunting.

The main limitation of this study is missing data on some variables, especially with respect to our intent to include all nutritional factors, including dietary habits which was limited due to missing data (almost 40\%) in the EDHS data set. Multiple imputation was beyond the scope this analysis. Moreover, AUC of the model we developed is not high because of missing or unmeasured variables which indicate the need for future supportive studies to improve its predictive ability. However, it evident from the descriptive statistics that, on average, very few (i.e., one in five of children) received adequate and diverse nutrition which included grains, animal and plant-based proteins, fruits and vegetables.

\section{Conclusion}

Our model indicates that being born male, being from a mother of short stature, living in a rural area, small child size, mother with mild anemia, father with no education or primary education only, low weight of the child, and over 24 months of age increases the likelihood of stunting. On the other hand, being born to an overweight or obese mother decreases the likelihood of stunting.

The model fits the data very well with an AUC of $77 \%$. Improving the nutritional and socioeconomic status of women pre-pregnancy and during pregnancy might reduce the burden of stunting.

Future studies are needed which focus on determining the association between body composition of the mother, medical conditions, and childhood stunting, finding another window of opportunity to minimize/ reverse the consequences in already stunted children, and impact of low child weight should receive due emphasis on future endeavors of reducing chronic malnutrition. Moreover, we recommend the DHS to include more robust, and a contextually customized objective dietary/ nutritional patterns questionnaires in upcoming surveys.

\section{Supplementary information}

Supplementary information accompanies this paper at https://doi.org/10. 1186/s40795-020-00378-Z.

Additional file 1: Table 1. EDHS variable codes, and explanation of variables included to this study.

Additional file 2 .

\section{Abbreviations}

AUC: Area under the curve; AIC: Akaike information criteria; BMI: Body mass index; EDHS: Ethiopian demographic health survey; ROC: Receiver operating curve; SD: Standard deviation; SSA: Sub-Saharan Africa; VIF: Variance inflation factor

Acknowledgments

We are thankful to DHS program coordinators for granting access to EDHS.

\section{Authors' contributions}

HGM: conceived the study, analyzed the data, wrote the draft manuscript and revised; HV: contributed to critical review and revision of the manuscript; CF: contributed in reviewing the manuscript, statistical review and edits; PP: participated in design, review and drafting the manuscript. The author(s) read and approved the final manuscript.

\section{Funding}

The authors did not receive any funding for preparation or publication of this manuscript.

\section{Availability of data and materials}

The data we analyzed in this study are publicly available at https://www. dhsprogram.com/data/dataset/Ethiopia_Standard-DHS_2016.cfm?flag $=0$.

\section{Ethics approval and consent to participate}

The protocol for the 2016 EDHS was approved by the Institutional Review Board (IRB) of ICF and the National Ethics Review Committee at the Ministry of Science and Technology. The authors obtained permission from the DHS program to download and use the data for this analysis.

Consent for publication

Not applicable.

\section{Competing interests}

The authors declared that there are no any competing interests.

\section{Author details}

'School of Public Health, University of Saskatchewan, Saskatoon, SK, Canada. ${ }^{2}$ Adigrat University, College of Medicine and Health Sciences, Adigrat, Ethiopia. ${ }^{3}$ College of Pharmacy and Nutrition, University of Saskatchewan, Saskatoon, SK, Canada. ${ }^{4}$ College of Nursing, University of Saskatchewan, Saskatoon, SK, Canada. ${ }^{5}$ Adjunct Nelson Mandela African Institute of Science and Technology, Arusha, Tanzania.

Received: 15 July 2020 Accepted: 3 September 2020

Published online: 22 September 2020

\section{References}

1. Woldehanna T, Jere RB, Araya MW. The effect of early childhood stunting on children's cognitive achievements: evidence from young lives Ethiopia. Ethiop J Heal Dev. 2017;31(2):75-84.

2. Dewey KG, Begum K. Long-term consequences of stunting in early life. Matern Child Nutr. 2011;7:5-18

3. de Onis M, Onyango A, Borghi E, Siyam A, Blössner M, Lutter C, et al. Worldwide implementation of the WHO child growth standards. SN Public Health Nutr. 2012;15:1603-10.

4. Black RE, Allen LH, Bhutta ZA, Caulfield LE, Onis M, Ezzati M, et al. Maternal and child under nutrition: global and regional exposures and health consequences. Lancet. 2008;371:243-60.

5. Grantham-McGregor S, Cheung YB, Cueto S, Glewwe P, Richter L. Child development in developing countries: developmental potential in the first 5 years for children in developing countries. Lancet. 2007;369:60-70.

6. Prendergast AJ, Humphrey JH. The stunting syndrome in developing countries Paediatrics and International Child Health 2014; 34(4): 250-265.

7. Yadav DK, Gupta N, Shrestha N. An assessment of nutritional status of children less than 3 years in rural areas of Mahottari district of Nepal. Int J Med Res Health Sci. 2014;3(3):597-603.

8. UNICEF/WHO/World Bank group joint malnutrition estimate. Levels and Trends in Child Malnutrition. Key findings of the 2018 edition.

9. WHO Multicenter Growth Reference Study Group. WHO child growth standards: length/ height-for-age, weight-for-age, weight-for-length, weight- 
for-height and body mass index-for-age: methods and development. Geneva: World Health Organization; 2006

10. Martorell R. Improved nutrition in the first 1000 days and adult human capital and health. Am J Hum Biol. 2017;29(2):10,

11. Central Statistical Agency/CSA/Ethiopia and ICF. Ethiopia Demographic and Health Survey 2016. Addis Ababa and Rockville: CSA and ICF; 2016.

12. ICF. EPHI (EPHI) [Ethiopia] and. Ethiopia Mini Demographic and Health Survey 2019: Key indicators. Rockville: EPHI and ICF. p. 2019.

13. Wondimagegn ZT. Magnitude and determinants of stunting among children in Africa: a systematic review. Curr Res Nutr Food Sci. 2014;2(2):88-93.

14. Abeway S, Gebremichael B, Murugan R, Assefa M, Adinew YM. Stunting and its determinants among children aged 6-59 months in northern Ethiopia: A cross-sectional study. J Nutr Metab. 2018(Article ID 1078480):8.

15. Birhanu A, Mekonen S, Atenafu A, Abebaw D. Stunting and associated factors among children aged 6-59 months in Lasta Woreda, north East Ethiopia, 2015: a community based cross-sectional study design. J Fam Med. 2017;4(3):1112

16. Geberselassie SB, Abebe SM, Melsew YA, Mutuku SM, Wassie MM. Prevalence of stunting and its associated factors among children 6-59 months of age in Libo-Kemekem district, Northwest Ethiopia; a community based cross-sectional study. PLoS One. 2018;13(5):e0195361.

17. Dewana Z, Fikadu T, Facha W, Mekonnen N. Prevalence and predictors of stunting among children of age between 24 to 59 months in Butajira town and surrounding district, Gurage zone, Southern Ethiopia. Health Sci J. 2017; 11(4):518.

18. Vilcins D, Sly PD, Jagals P. Environmental risk factors associated with child stunting: a systematic review of the literature. Ann Glob Health. 2018;84(4): 551-62.

19. Haile D, Azage M, Mola T, Rainey R. Exploring spatial variations and factors associated with childhood stunting in Ethiopia: spatial and multilevel analysis. BMC Pediatr. 2016;16:49.

20. Tigga P, Sen J. Maternal body mass index is strongly associated with children Z-scores for height and BMI. J Anthropol. 2016(Article ID 6538235):10.

21. Hernández-Díaz S, Peterson KE, Dixit S, Hernández B, Parra S, Barquera S, et al. Association of maternal short stature with stunting among Mexican children: common genes vs common environment. Eur J Clin Nutr. 1999; 53(12):938-45.

22. Myatt M, Khara T, Schoenbuchner S, Pietzsch S, Dolan C, Lelijveld N, et al. Children who are both wasted and stunted are also underweight and have a high risk of death: a descriptive epidemiology of multiple anthropometric deficits using data from 51 countries. Arch Public Health. 2018;76:28.

23. Richard SA, Black RE, Gilman RH, Guerrant RL, Kang G, Lanata CF. Wasting is associated with stunting in early childhood. J Nutr. 2012;142:1291-6.

24. Uwiringiyimana V, Ock MC, Amer S, Veldkamp A. Predictors of stunting with particular focus on complementary feeding practices: A cross-sectional study in the northern province of Rwanda Nutrition, vol. 21; 2018. p. 334-42.

25. Demirchyan AA, Petrosyan V, Sargsyan V, Hekimian Z. Predictors of stunting among children ages 0 to 59 months in a rural region of Armenia. JPGN 2016;62:150-6.

26. Willey BA, Cameron N, Norris SA, Pettifor JM, Griffiths PL. Socioeconomic predictors of stunting in preschool children - a population-based study from Johannesburg and Soweto. S Afr Med J. 2009;99:450-6.

27. Hambidge KM, Mazariegos M, Kindem M, Wright LL, Cristobal-Perez C, Juárez-García L, et al. Infant stunting is associated with short maternal stature. J Pediatr Gastroenterol Nutr. 2012;54(1):117-9.

28. Central Statistical Agency (CSA) Ethiopia. Ethiopia Demographic and Health Survey 2011. Addis Ababa and Calverton: CSA and ORC Macro; 2012.

29. World Health Organization. Indicators for assessing infant and young child feeding practices: part I. Geneva: WHO; 2008.

30. Campisi SC, Cherian AM, Bhutta ZA. World perspective on the epidemiology of stunting between 1990 and 2015. Horm Res Paediatr. 2017;88(1):70-8.

31. Wells JCK, Devakumar D, Manandhar DS, Chaube NSS, Costello A, Osrin D. Associations of stunting at 2 years with body composition and blood pressure at 8 years of age: longitudinal cohort analysis from lowland Nepal. Eur J Clin Nutr. 2019;73:302-10.

32. Perumal N, Bassani DG, Roth DE. Use and misuse of stunting as a measure of child health. J Nutr. 2018;148:311-5.

33. Wu BN, O'Sullivan AJ. Sex differences in energy metabolism need to be considered with lifestyle modifications in humans. J Nutr Met. 2011;(Article ID 391809):6.
34. Henry W, Anne NÅ, Stefan P, James KT, Thorkild T. Boys are more stunted than girls in sub-Saharan Africa: a meta-analysis of 16 demographic and health surveys. BMC Pediatr. 2007;7:17.

35. UN General Assembly. Transforming our world: The 2030 Agenda for sustainable development, 2015. Available at: https://www.refworld.org/ docid/57b6e3e44.html [accessed 9 February 2019].

36. Central Statistical Authority/Ethiopia and ORC Macro. Ethiopia demographic and health survey 2000. Addis Ababa: Central Statistical Authority/Ethiopia and ORC Macro; 2001. Available at http://dhsprogram.com/pubs/pdf/FR118/ FR118.pdf.

\section{Publisher's Note}

Springer Nature remains neutral with regard to jurisdictional claims in published maps and institutional affiliations.
Ready to submit your research? Choose BMC and benefit from:

- fast, convenient online submission

- thorough peer review by experienced researchers in your field

- rapid publication on acceptance

- support for research data, including large and complex data types

- gold Open Access which fosters wider collaboration and increased citations

- maximum visibility for your research: over $100 \mathrm{M}$ website views per year

At BMC, research is always in progress.

Learn more biomedcentral.com/submissions 